\title{
HCV clearance by direct antiviral therapy and occurrence/recurrence of hepatocellular carcinoma: still an issue?
}

\author{
Francesco Paolo Russo, Martina Tessari, Angela Imondi, Erica Nicola Lynch, Fabio Farinati \\ Department of Surgery, Oncology and Gastroenterology, Section of Gastroenterology, Padua University Hospital, Padua 35128, Italy. \\ Correspondence to: Prof. Fabio Farinati, Department of Surgery, Oncology and Gastroenterology, Section of Gastroenterology, Padua \\ University Hospital, Via Giustiniani 2, Padua 35128, Italy. E-mail: fabio.farinati@unipd.it
}

How to cite this article: Russo FP, Tessari M, Imondi A, Lynch EN, Farinati F. HCV clearance by direct antiviral therapy and occurrence/ recurrence of hepatocellular carcinoma: still an issue? Hepatoma Res 2018;4:25. http://dx.doi.org/10.20517/2394-5079.2018.52

Received: 4 May 2018 First Decision: 15 May 2018 Revised: 10 Jun 2018 Accepted: 16 Jun 2018 Published: 27 Jun 2018

Science Editor: Guang-Wen Cao Copy Editor: Jun-Yao Li Production Editor: Huan-Liang Wu

\begin{abstract}
New regimens with direct-acting antivirals (DAAs) agents have changed both efficacy and safety of hepatitis $C$ virus (HCV)-treatment, as almost all patients can be treated and cured at any stage of liver disease. The rates of sustained virological response to currently available combinations exceed $95 \%$ in real-life practice. However, conflicting results have been produced on the occurrence/recurrence of hepatocellular carcinoma (HCC) in patients with $\mathrm{HCV}$-associated cirrhosis treated with DAAs. In this review we analyse the data available in the literature in order to elucidate the impact of DAAs on the risk of HCC occurrence in patients without previous history of tumor, and of recurrence after successful treatment of the tumor. Data on "de novo" HCC incidence were quite homogeneous, suggesting that the treatment with DAAs does not modify the risk of HCC developing during the first 6-12 months after HCV eradication. On the contrary, HCC recurrence rates after DAAs were extremely variable across different studies, reflecting a large heterogeneity in this clinical setting. The possibility that treatment with DAAs may favour tumour growth and spread in individual patients with active HCC foci is supported by some observations but remains unproven.
\end{abstract}

Keywords: Hepatitis C virus, direct-acting antivirals, eradication, hepatocellular carcinoma, occurrence, recurrence

\section{INTRODUCTION}

Patients with hepatitis $\mathrm{C}$ infection ( $\mathrm{HCV}$ ) and cirrhosis have an increased risk of developing liver decompensation (LD), hepatocellular carcinoma (HCC) and liver-related death (LRD). Cirrhosis is a major risk factor for the development of HCC in Western countries, where HCC occurs at an average annual rate of $3 \%-5 \%$ in cirrhotic patients ${ }^{[1,2]}$. Data on the long-term outcome of patients with HCV infections,

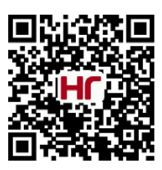


treated with Peg-interferon (Peg-IFN) and ribavirin, demonstrated a reduction in LRD and non-LRD, with patients achieving sustained virological response (SVR) showing nearly the same life expectancy as the general population ${ }^{[3,4]}$. Patients with compensated cirrhosis, and without the clinical manifestations of portal hypertension, are those who experience the greater clinical benefits of HCV eradication, as they do not develop LD and rarely HCC $^{[5]}$.

This was confirmed in a meta-analysis of 12 studies including 25,497 patients that demonstrated a relative risk reduction for HCC at all stages of liver disease [hazard ratio (HR): $0.24 ; 95 \% \mathrm{CI}$ : $0.18-0.31 ; P=0.001$ ] and an absolute risk reduction of $4.6 \%$ (95\%CI: $4.2 \%-5.0 \%$ ) in patients who achieved SVR compared to those who did not respond ${ }^{[6]}$.

\section{DIRECT-ACTING ANTIVIRAL THERAPY: A NEW STORY HAS STARTED}

The more widely extended indication criteria and the greater affordability of direct-acting antiviral (DAA) therapy is leading to higher rates of HCV eradication and is expected to reduce the risk of HCC by preventing, at least in part, liver cirrhosis. Nevertheless, in cirrhotic patients, particularly in those with concurrent pro-carcinogenic co-factors, such as diabetes and/or advanced age, the risk of HCC remains elevated for several years after SVR. This underlines the importance of HCC surveillance even after SVR in cirrhotic patients and highlights the need for early initiation of DAA therapy, before cirrhosis is established ${ }^{[7]}$. Cabibbo et al.$^{[8]}$ published a meta-analysis of the HCV-untreated arms of the studies evaluating the outcomes of patients with early HCC who, after a successful treatment of the tumour, did not receive any antiviral treatment. This study provides a benchmark for indirect future comparisons aimed to determine the actual benefit of HCV eradication by antiviral treatment. They found an extremely variable 2 and 3-year HCC recurrence rate, respectively at $47 \%$ and $79.8 \%$, in patients HCV-infected who did not receive antiviral therapy, and this heterogeneity was not completely explained by any single patient or study characteristic.

\section{DAA AND HCC: HIGHER OCCURRENCE/RECURRENCE}

In 2014, the introduction of DAAs has revolutionized the standard of care of HCV infection, allowing to reach SVR rates of over $90 \%$ in patients with genotype 1. Multiple oral interferon-free HCV regimes are now available and, although there is some evidence of response variability, related to specific patient characteristics and HCV genotypes, the SVR rates are high for all approved DAAs. Due to their high efficacy, tolerability and the relatively short treatment duration, DAAs are now the standard care for patient populations that were historically considered difficult to cure ${ }^{[9]}$, even though data on the long-term outcome of patients with advanced liver disease treated with DAAs are still lacking.

The assumption that HCV eradication would translate into a reduced incidence of newly developed tumours in HCV patients as well as into a reduced HCC recurrence rate, is to be considered in the context of the controversy about a potential association between DAA treatment and an increased HCC risk, overall [Table 1].

In fact, in 2016 a report ${ }^{[10]}$ described a totally unexpected early tumor recurrence in patients with HCVrelated HCC undergoing DAA treatment.

In a cohort of patients who achieved a complete HCC radiological response before starting antiviral treatment with DAAs, Reig et al. ${ }^{[10]}$ described an HCC recurrence rate of $28 \%$ (16 of 58 patients), with a median follow-up of only 6 months, recurrence rate that was extremely higher than expected and previously observed. Furthermore, the pattern of relapse was described as infiltrative or multinodular in $25 \%$ cases, this also being an unexpected finding. Even though the authors concluded that their data should only be taken as a "note of caution", and that large-scale studies were necessary to confirm their results, this report raised a debate about the risk of DAA treatment and suggested that a stricter pharmacovigilance action 
should be undertaken by all prescribers and regulators involved in this issue. The above-mentioned study also led to the hypothesis that HCV eradication mediated by DAAs may induce a sudden modification in HCV-dependent inflammatory status and immune surveillance, dysregulating the anti-tumor response and boosting the growth of still undetected HCC foci. Recurrence after initial complete response may be explained by the dissemination of cells prior to treatment, and by the development of new oncogenic clones within a cirrhotic liver that has already suffered genetic damage. Immune surveillance plays a major role in regulating survival and growth of metastatic cells; DAA-based antiviral treatment, as a consequence of the inhibition of HCV replication and the abrupt resolution of chronic inflammation, may disrupt cancer immunosurveillance. This may lead to tumor progression.

A similar report on the management of patients with HCC undergoing DAA treatment was elaborated by Conti et al. ${ }^{[1]}$. Their data suggested that DAA-induced resolution of HCV infection did not decrease the occurrence of HCC in the short term and that HCC curative treatments, in patients undergoing antiviral therapy, do not reduce the risk of recurrence. In their study the recurrence rate of patients with a history of previous liver cancer was around 30\% (17 of 59 patients) within 24 weeks. In contrast with the study by Reig et al. ${ }^{[10]}$, the patients who experienced HCC recurrence were younger and had a more severe liver stiffness. Another study, published by Kozbial et al. ${ }^{[12]}$, reported an unexpected high incidence of HCC occurrence and recurrence in patients treated with DAAs. Even though the study included a small number of patients, the authors concluded that decreasing inflammation could have a role in modulating liver regeneration and that the change in the immunological environment could induce the progression of preexisting pre-cancerous changes ${ }^{[12,13]}$. The authors also noticed the reduction of miR-22 levels in patients treated with DAAs, which could play a possible role in tumor development, since miR-22 is involved in suppressing the replication of virus-infected cells and controlling carcinogenesis ${ }^{[14]}$.

As suggested by Reig et al. ${ }^{[15]}$, tumor dormancy derives from a dynamic equilibrium between cancer cells growth and immune cells infiltration; several conditions and DAA treatment could disturb this equilibrium by causing immunological changes, connected to the fall of the antigenic load due to HCV eradication. This phenomenon was not observed in patients who underwent IFN-based therapy, probably because of the immune-modulatory and anti-proliferative properties of $\operatorname{IFN}^{[16]}$. Moreover, chronic HCV infection activates the most prevalent innate cells in the liver, the NK cells, as well as increases the expression of IFN-stimulated genes, suggesting that infection activates an intrahepatic immune response. In fact, DAAmediated HCV eradication is characterized by decreased levels of CXCL10 and CXCL11 and normalization of NK-cell phenotype and function, a fact that could explain the association between HCV clearance and loss of intrahepatic immune reactivation ${ }^{[17,18]}$.

Cardoso et al ${ }^{[19]}$ in a study of a cohort of 54 patients successfully treated with IFN-free antiviral therapy, reported an HCC incidence of 7.4\% after a median time of 7.6 months (IQR 6.3-10.6 months), in a median follow-up of 12 months (IQR 9.4-12.5 months). The authors, in agreement with Reig et al ${ }^{[15]}$, speculated that an oncogenic effect of the antiviral therapy was highly unlikely, but at the same time, due to the coincidence with viral elimination, the mechanisms responsible could be those previously hypothesized.

A recent report by Abdelaziz et al. ${ }^{[20]}$ distinguished de novo vs. recurrent HCC following DAA treatment and evaluated their behaviour. No difference was found regarding patient baseline and tumor characteristics (age, gender, hepatic function assessed by Child Pugh Score, performance status, number or size of lesions) or their response to DAAs. On the opposite, a significantly different time before detection of HCC emerged between the two groups. De novo lesions developed later than recurrent tumors (14 \pm 16.02 vs. $6.7 \pm$ 5.1 months, $P=0.008)$ and showed a better response to ablation $(P=0.03)$. The above-mentioned studies represent the current bulk regarding the evidence of DAAs promoting liver carcinogenesis. 


\section{DAA AND HCC: JUST FICTION?}

On the other hand, other published articles did not confirm the higher occurrence or recurrence of HCC in patients treated with IFN-free, DAA-based therapy. Strong evidence against this assumption was given by three French prospective multicentre studies by the Agency for Research on AIDS and Viral Hepatitis (ANRS in the French acronym) cohorts of DAA-treated HCV-infected patients treated with curative HCC therapies $^{[21]}$. In detail, the rates of recurrence in the ARNS CO22 HEPATHER cohort (including 189 DAA+ and 78 DAA- patients) were $0.73 / 100$ and $0.66 / 100$ person-months respectively in the DAA+ and the DAAgroup. In the ARNS CO12 CirVir cohort, the rates were 1.11/100 in $13 \mathrm{DAA}+$ and 1.73/100 person-months in 66 DAA-. Finally, the ARNS CO23 CUPILT cohort of HCC liver transplant recipients, successively treated with IFN-free antiviral therapy, showed a recurrence rate of $2 \%$ (7/314 patients). Notwithstanding the large number of patients that were analysed in these studies, no increase in the risk of HCC recurrence after antiviral therapy was detected in any of the cohorts. The recurrence rates did not differ between treated and untreated patients. A sharp criticism towards the ANRS study design was made by Kolly and Dufour ${ }^{[22]}$ stating that it artificially decreased the rate of HCC recurrence in untreated patients. The ARNS collaborative group argued, as a defence of the accuracy of the design of the study, that treatment was considered as time-dependent variable and that patients who underwent treatment were considered part of the untreated group until the therapy started ${ }^{[23]}$. A study in an English cohort, including more than 400 treated patients, supported the French findings. Also, Cheung et al. ${ }^{[24]}$, after a follow-up of 12 months, revealed a reduction in HCC rates after HCV eradication in DAA-treated patients. The preliminary data of another prospective observational study of patients with liver cancer and HCV infection treated with DAAs, show no HCC recurrence after curative treatment in a median follow-up of 12 months ${ }^{[25]}$. Furthermore, the study by Zavaglia et al. ${ }^{[26]}$ did not confirm the alarming findings of Reig and Conti: amongst the 31 patients they followed, they only observed 1 case of liver cancer, with a median follow-up of 8 months. The longer interval between complete HCC curative treatment and antiviral therapy (median 19 months in Zavaglia's experience vs. 11 months in Reig's study) could partly explain the contrasting results. It appears that, the longer the interval between tumor eradication and antiviral therapy initiation, the lower the risk that residual tumoral cells are still present at the beginning of DAA treatment ${ }^{[26]}$, and this is highly conceivable.

Cabibbo et al ${ }^{[27]}$ in a prospective study of 143 patients with previously successfully treated HCC, then treated with DAAs, showed 6-, 12- and 18-month recurrence rates of $12 \%, 26 \%$ and $29.1 \%$ respectively; in this group of patients, the authors found comparable results to those observed in DAA-unexposed patients. Previous history of HCC recurrence (HR: 2.22; 95\%CI: 1.02-4.83; $P=0.043$ ) and tumor size (HR: 2.73; 95\%CI: $1.23-$ 6.06; $P<0.014)$ were the two independent risk factors for HCC early recurrence that could be used to stratify the risk of HCC recurrence. A large amount of data was analysed by Waziry et al ${ }^{[28]}$ in a meta-analysis and meta-regression analysis based on 41 studies: no evidence of increased HCC occurrence or recurrence risk after DAA therapy vs. INF-based therapy was found. HCV eradication was confirmed to decrease HCC risk in patients who achieved SVR, whereas older age, advanced cirrhosis and worse patient baseline characteristics in DAA-treated population were independent predictors of HCC development and provide an explanation of the apparently higher risk (3.1 vs. 1.1/100 per years). Another study was conducted by Ioannou et al. ${ }^{[29]}$ on a large cohort of HCV infected cirrhotic patients from the Veterans Affairs national healthcare system, treated with IFN regimen alone, DAA regimen or INF+DAAs, during a 6.1 years mean follow-up. A 71\% HCC occurrence risk reduction was associated with DAAs-induced SVR compared to treatment failure, but the reduction was similar, irrespective of how SVR was achieved (DAA-only AHR: 0.29; 95\%CI: 0.23-0.37; DAA + INF AHR: 0.48; 95\%CI: 0.32-0.73; IFN-only: 0.32; 95\%CI: 0.28-0.37). Maan and Feld $^{[30]}$ are also amongst the authors supporting the association between SVR achievement and HCC risk reduction due to the analysis of a retrospective study on cohorts of veterans treated with DAAs. In a study by Kobayashi et al. ${ }^{[31]}, 77$ patients treated with DAAs, who achieved SVR, were compared to 528 patients who underwent viral eradication with Peg-IFN/RBV during a median follow-up of 4 years. Amongst DAA-treated patients, 2.6\% developed liver cancer, while the 3- and 5-year cumulative HCC development rates were $1.30 \%$ 
and $3 \%$ in the IFN-free treatment group and $1 \%$ and $2.2 \%$ in the Peg-IFN/RBV group, with no statistically significant differences ${ }^{[31]}$. A European multicentre study by Kolly et al. ${ }^{[32]}$ assessed the HCC recurrence rate after DAA treatment, reported as the cumulative disease-free survival during the follow-up. In 47 patients previously treated for HCC, the time between tumor treatment and the initiation of DAAs was a predictor of recurrence, but whether this effect was due to the anti-viral therapy, or due to foci of HCC which were undetectable before treatment was undefined. Petta et al. ${ }^{[33]}$, using the ITA.LI.CA liver cancer collaborative database, demonstrated that the eradication achieved by both IFN-based therapy and DAAs resulted in an increased time before tumour recurrence in patients with HCC curatively treated by radical ablation. Data deriving from their observation showed $16(28 \%)$ and 22 cases (39\%) of HCC, after a median follow-up of 18 months in DAA, and 34 months in IFN-based SVR, respectively.

Also, the retrospective large cohort study performed by Kanwal et al. ${ }^{[34]}$ on DAA-treated patients from 129 Veterans Health Administration centres confirmed the lack of evidence that DAAs promote HCC and the preventive effect of the HCV eradication on HCC occurrence, with a $76 \%$ risk reduction. On the other hand, their analysis confirmed that the HCC risk persists despite SVR in DAA-treated patients, with an annual HCC incidence after HCV eradication with DAAs of $0.90 \%$, compared to $0.3 \%$ in IFN-treated patients (as reported by previous studies). It must be said that the treated population has changed since the advent of DAAs, thus giving patients with other independent HCC risk factors, such as advanced cirrhosis, a chance to be treated. The incidence rate was greater in cirrhotic patients, underlying the importance of HCC surveillance in this scenario, as well as the need of not delaying treatment in order to avoid liver deterioration.

A retrospective population-based cohort study using the Electronically Retrieved Cohort of HCV Infected Veterans (ERCHIVES) investigated whether DAA use was associated with higher rates of incident HCC compared to treatment with IFN-based regimes, the primary outcome being the development of incident HCC cases. A series of 17,836 persons was included, and amongst cirrhotic patients DAA treatment was not associated with higher risk of HCC compared to the IFN-treatment group (HR: 1.07; 95\%CI: 0.55-2.08). The risk of incident HCC was higher, among patients with known HCC risk factors including older age (HR, per 10 years increased: 1.76 ; 95\%CI: 1.26-2.16) and AFP > 20 (HR: 4.1; 95\%CI: 2.75-6.10), but when an analysis in cirrhotics was performed, there were no differences in HCC-free survival between the DAA-treated and IFN group. According to the authors, this suggests that pre-treatment HCC risk is the factor that determines post-treatment risk. In contrast, untreated cirrhotic patients had a significantly higher incidence rate of HCC compared to both DAA and IFN treated groups (45.31 per 1000 person-years; $P=0.03)^{[35]}$.

Very recently large cohort studies using real-world data demonstrated that DAA-based HCV treatment is not associated with an increased risk of incident liver cancer and suggested that DAA-based HCV treatments are associated with a reduced risk of incident liver cancer, irrespective of co-medication with interferon. Male gender, older age and baseline cirrhosis were the strongest predictors independently associated with subsequent incident liver cancer ${ }^{[36]}$. It's been demonstrated that reaching SVR allows all-cause mortality reduction, including HCC-related mortality, for all stages of hepatic disease. In advanced liver disease, this was first proven when SVR was reached with IFN-based regimens ${ }^{[37]}$. In the above mentioned study by Cheung et al. ${ }^{[24]}$ on DAA treatment in patients with decompensated hepatic disease, HCC incidence in patients with SVR24 was lower than in those who did not accomplish it $(17 / 317,5.4 \%$ vs. 10/89, $11.2 \%$; $P=0.049$; HR: 0.33; 95\%CI: 0.13-0.87). The results were compared to HCC incidence in untreated patients (4.2\%). There was no evidence of a significant increase in HCC occurrence in treated patients ${ }^{[24]}$.

Another interesting scenario is liver transplantation, and the clinical impact of viral eradication in patients on waiting list is still poorly evaluated. 
Table 1. Current literature about the possible association between antiviral therapy DAAs based and the risk of HCC development

\begin{tabular}{|c|c|c|c|c|c|c|c|c|}
\hline $\begin{array}{l}\text { Authors } \\
\text { (country) }\end{array}$ & Study population & $\begin{array}{l}\text { Mean FU } \\
\text { after } \\
\text { DAAs } \\
\text { (months) }\end{array}$ & $\begin{array}{l}\text { Occurrence } \\
\text { (DAAs) }\end{array}$ & $\begin{array}{l}\text { Occurrence } \\
\text { (controls) }\end{array}$ & $\begin{array}{l}\text { Recurrence } \\
\text { (DAAs) }\end{array}$ & $\begin{array}{l}\text { Recurrence } \\
\text { (controls) }\end{array}$ & $\begin{array}{l}\text { Pos-LT } \\
\text { recurrence } \\
\text { (DAAs) }\end{array}$ & $\begin{array}{l}\text { Post-LT } \\
\text { recurrence } \\
\text { (controls) }\end{array}$ \\
\hline $\begin{array}{l}\text { Reig et al. }{ }^{[10]} \\
\text { (Spain) }\end{array}$ & $\begin{array}{l}58 \text { cirrhotic patients } \\
\text { with previous } \\
\text { HCC (complete } \\
\text { radiological } \\
\text { response) }\end{array}$ & 5.7 & NA & NA & $\begin{array}{l}\text { 16/58* }(28 \%) ; \\
25 \% \text { were } \\
\text { multinodular } \\
\text { /infiltrative } \\
\text { *Median time } \\
\text { interval between } \\
\text { HCC complete } \\
\text { eradication } \\
\text { and the start of } \\
\text { therapy was } 11.2 \\
\text { months }\end{array}$ & NA & NA & NA \\
\hline $\begin{array}{l}\text { Conti et } a / .^{[11]} \\
\text { (Italy) }\end{array}$ & 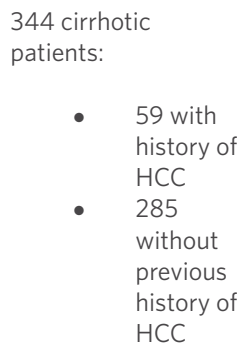 & Pold & $\begin{array}{l}9 / 285 \\
(3.2 \%)\end{array}$ & NA & $\begin{array}{l}17 / 59^{\star} \\
(28.8 \%) \\
{ }^{\star} \text { Younger age } \\
\text { and severe } \\
\text { fibrosis } \\
\text { associated with } \\
\text { recurrence }\end{array}$ & NA & NA & NA \\
\hline $\begin{array}{l}\text { Kozbial et al. }{ }^{[12]} \\
\text { (Austria) }\end{array}$ & \multicolumn{2}{|c|}{$\begin{array}{l}16 \text { patients who } \\
\text { developed } \mathrm{HCC} \\
\text { ( } 3 \text { of them with } \\
\text { previous history of } \\
\text { HCC but successfully } \\
\text { treated and in } \\
\text { complete remission } \\
\text { for }>3 \text { years; } 3 \\
\text { patients were F3, } 5 \\
\text { patients relapsed) }\end{array}$} & NA & NA & NA & $\begin{array}{l}\text { Historical } \\
\text { group of } 94 \\
\text { cirrhotic pts } \\
\text { with SVR } \\
\text { after with } \\
\text { IFN/RBV } 10 \\
\text { developed a } \\
\text { HCC within a } \\
\text { mean follow- } \\
\text { up of } 7.8 \\
\text { years }\end{array}$ & NA & NA \\
\hline $\begin{array}{l}\text { Cardoso et al. }{ }^{[19]} \\
\text { (Portugal) }\end{array}$ & $\begin{array}{l}54 \text { patients } \\
\text { (patients with } \\
\text { "non-characterized } \\
\text { nodules" and/or a } \\
\text { previous diagnosis of } \\
\text { HCC were excluded) }\end{array}$ & 12 & $\begin{array}{l}4 / 54^{\star} \\
(7.4 \%) \\
{ }^{\star} \text { No } \\
\text { significant } \\
\text { differences } \\
\text { in baseline } \\
\text { variables } \\
\text { that could be } \\
\text { associated } \\
\text { with an } \\
\text { increased } \\
\text { HCC risk } \\
\text { were found }\end{array}$ & NA & NA & NA & NA & NA \\
\hline \multirow[t]{2}{*}{$\begin{array}{l}\text { Yang et al. }{ }^{[38]} \\
\text { (USA) }\end{array}$} & $\begin{array}{l}81 \text { patients who } \\
\text { underwent LT for } \\
\text { HCC: }\end{array}$ & & $\mathrm{NA}$ & NA & NA & NA & $\begin{array}{l}5 / 18 \#^{\star} \\
(27.8 \%)\end{array}$ & $\begin{array}{l}6 / 63 \#^{\star} \\
(9.5 \%)\end{array}$ \\
\hline & $\begin{array}{ll}\text { - } & 18 \rightarrow \\
\text { pre-LT } \\
\text { DAA (3 } \\
\text { of them } \\
\text { treated } \\
\text { with IFN } \\
\text { based } \\
\text { therapy) } \\
\text { 63 } \rightarrow \text { no } \\
\text { pre-LT } \\
\text { therapy }\end{array}$ & & & & & & $\begin{array}{l}\text { *Proportion } \\
\text { of pta beyond } \\
\text { Milan (explant } \\
\text { pathology) } \\
\text { higher in DAA } \\
\text { than controls; } \\
\text { no difference } \\
\text { in terms of } \\
\text { microvascular } \\
\text { invasion } \\
\text { and HCC } \\
\text { differentiation }\end{array}$ & $\# P=N S$ \\
\hline
\end{tabular}




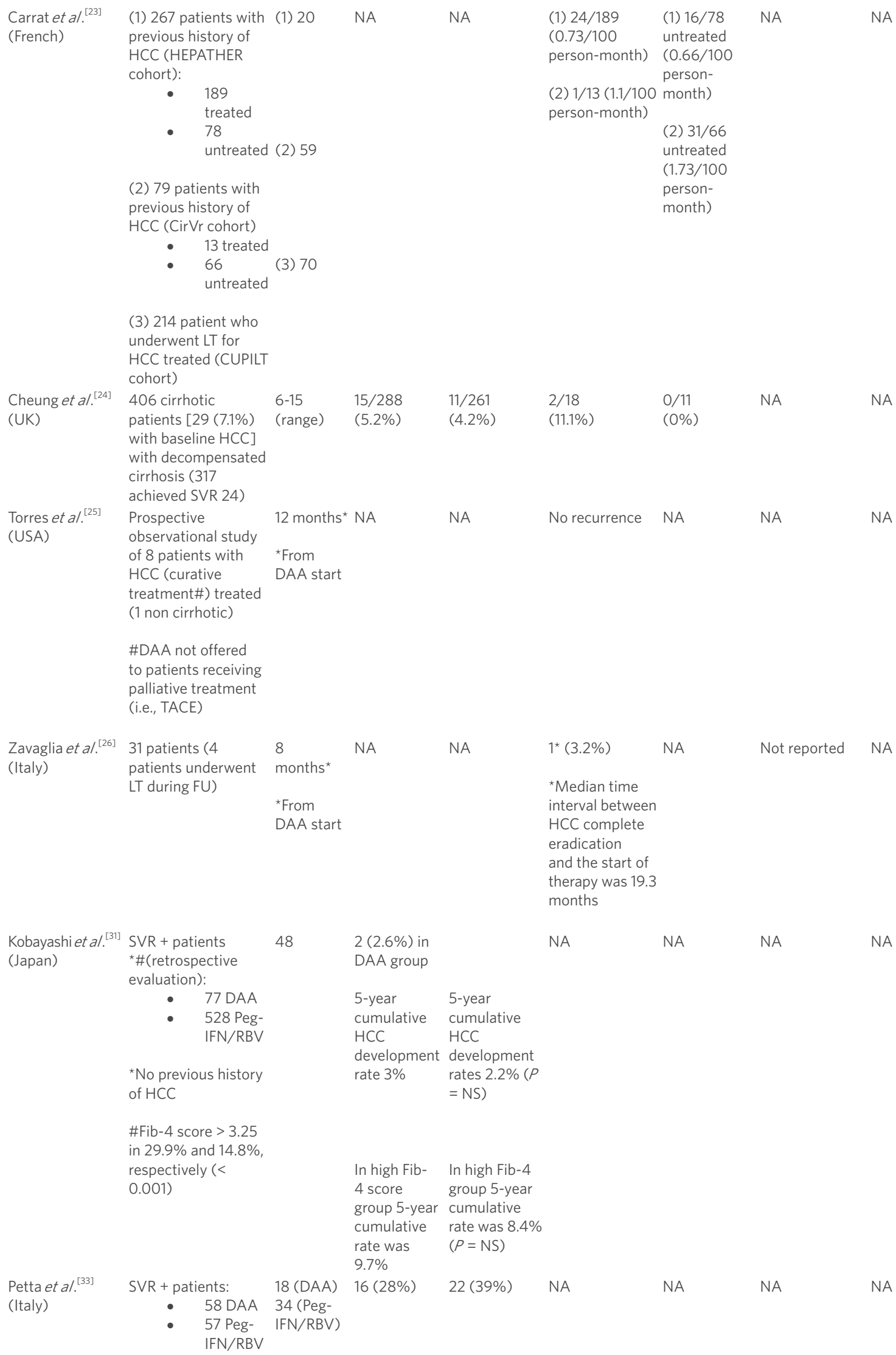




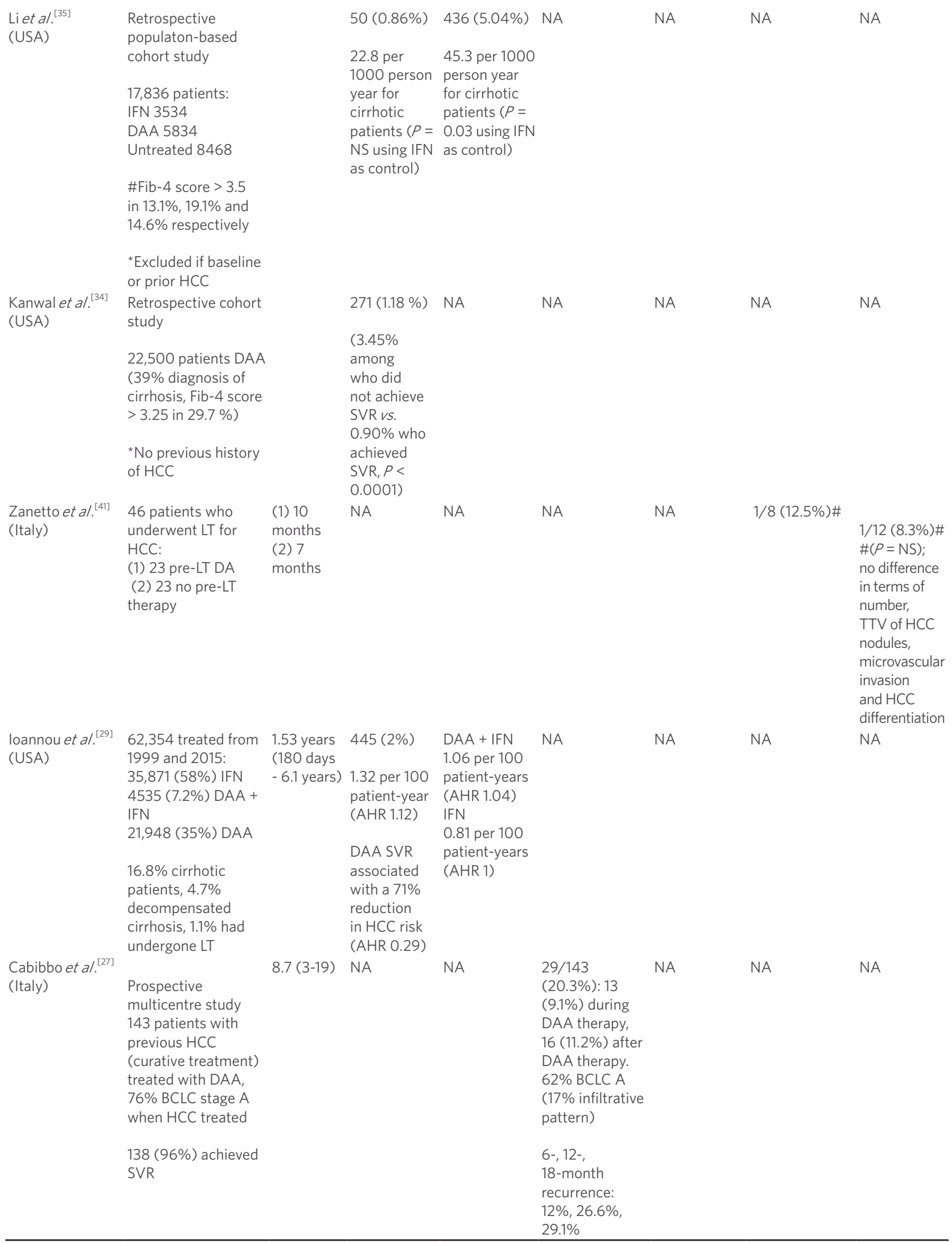

DAAs: direct-acting antivirals; HCC: hepatocellular carcinoma; LT: liver transplantation; FU: follow-up; BCLC: Barcelona Clinic Liver Cancer; SVR: sustained virological response; AHR: adjusted hazard ratio; IFN: interferon; TACE: transarterial chemoembolization; RBV: ribavirin; NA: not available; NS: not significant 
A study showed a high risk of HCC recurrence in patients treated with DAAs before liver transplantation (LT) (5 of 18 patients, 28\%) compared to untreated ( 6 of 63 patients, 9.5\%). However, the difference did not reach statistical significance because of the small number of patients enrolled ${ }^{[38]}$, a series definitely too limited to provide any information.

Belli et al.$^{[39]}$ published data from a European study, investigating the probability of delisting after DAA treatment. In this study the cumulative incidences of inactivation and delisting at 60 weeks were $33 \%$ and $19.2 \%$ respectively. In another recent study published by Pascasio et al. ${ }^{[40]}, 238$ patients treated with DAAs while awaiting LT were enrolled, and $24 \%$ of the patients with decompensated cirrhosis were delisted after a median follow-up period of 50 weeks, as a result of clinical improvement, which appeared to remain stable in most patients. Indeed, only $9 \%$ of the patients were delisted because of HCC progression and the rate of microvascular invasion was $11 \%$, similar to what reported in previous studies. Although these data do not indicate an increase in HCC progression, the lack of untreated patients as a control group is a limitation. As a consequence, the use of DAA therapy in HCC patients awaiting LT cannot be strongly recommended. As far as SVR is concerned, in the above-mentioned study SVR rates were similar in patients with and without HCC ( $87 \%$ vs. $84 \%, P=0,560)$, and amongst patients with HCC there were no significant differences regarding tumor characteristics or BCLC staging comparing those with or without SVR.

In a recent retrospective study, conducted at the Padua Liver Transplant Centre, we investigated whether patients, listed for HCC and treated with DAAs, have an increased rate of tumor progression and consequently drop out from waiting list. Two groups (including 23 patients each) were evaluated, who underwent DAA therapy while awaiting LT or not. The two groups did not show any significant difference in terms of dropout rate, during a median follow-up of 10 and 7 months. Interestingly, a significantly lower probability of being transplanted was detected in the group of treated patients in comparison with the untreated, suggesting an improvement of liver function. With regard to post-LT recurrence of HCC, similar rates were found in the two groups (12.5\% in DAA-treated $v$ s. $8.3 \%$ in untreated group), suggesting that the risk of tumor recurrence was not higher in patients treated with DAA pre-LT than in those treated post-LT. Furthermore, liver explant histopathological analysis revealed similar HCC patterns in the 2 groups ${ }^{[4]]}$.

\section{DAA AND HCC: HISTOLOGICAL PATTERN}

Reig et al ${ }^{[10]}$ in their pivotal study also expressed concern about the histological pattern of HCC recurrence in patients treated with DAA therapy. In agreement with Reig's study, Romano et al.$^{[42]}$ demonstrated that about $30 \%$ of HCC presented with an infiltrative and/or multifocal pattern in a multi-centre cohort of cirrhotic patients treated with DAAs, even though their data on HCC incidence were in contrast with Reig's results. The more aggressive pattern of HCC was seen somehow more frequently (54.6\%) in patients without SVR compared to those with SVR (12.1\%) in which the single nodule pattern prevailed (69.7\%).

Nakao et al ${ }^{[43]}$ also investigated the pattern of HCC recurrence and de novo development, reporting six cases of de novo HCC out of 242 patients. All of the patients had been submitted to DAAs treatment, and all showed SVR. In all six cases HCC was pathologically diagnosed, allowing inferences about tumor characteristics and kinetics. All tumours were single nodules, moderately differentiated and rapidly growing, the authors were therefore led to hypothesize that HCC carcinogenesis after DAA therapy occurs in a nonconventional, multi-step manner.

\section{DAA AND HCC: ONLY IMMUNOLOGICAL ISSUE?}

It is recognized that the immune system plays a key role in modulating tumour development, but a report by Debes et al ${ }^{[44]}$ attempted to distinguish the immuno-related changes by measuring 22 different soluble immune mediators in patients who developed HCC (both de novo and recurrent) after HCV treatment 
with DAAs, comparing them to matched controls without HCC. Each marker was measured before and after DAA treatment, and very interestingly 12 of them, including apoptosis markers, cytokines and growth factors, resulted significantly higher before treatment in patients who developed de novo HCC, compared to controls. The authors suggested that a different immunologic pattern could be already present in patients who eventually develop HCC, before the immune changes due to DAAs occur. The immune background could therefore be a decisive factor in HCC development. Individuals who develop HCC may express a different pattern of immune mediators, that induces ongoing carcinogenic or pre-carcinogenic activity, prior to the appearing of HCC. In addition, TNF alpha levels remained stable or trended up during the first month of DAA treatment (with viral load being undetectable in serum) in patients who developed HCC, while decreasing in controls. TNF alpha could therefore be directly involved in HCC development even if $\mathrm{HCV}$ is absent, or on the other hand its production could be stimulated by the presence of occult tumor foci in the liver. Finally, this study suggested that tumorigenesis occurred with different characteristics in HCC recurrence compared to de novo HCC after DAAs, as IL-6 levels, were shown to be increased at the end of therapy in patients with HCC recurrence, while the levels of the cytokine showed a trend toward reduction in patients with de novo tumor. Again, these results should be interpreted with caution and additional studies could help to clarify their interpretation.

\section{HCC AND DAA: POSSIBLE ROLE IN RESPONSE TO ANTIVIRAL THERAPY AND NATURAL HISTORY OF DISEASE?}

Another matter of debate is whether the presence of HCC can influence the response to HCV therapy with direct-acting antivirals, and what could be the mechanism behind it. According to Prenner et al. ${ }^{[45]}$, the presence of active HCC (and not merely a history of tumor) when starting HCV therapy was the strongest predictor of treatment failure, with an eight-fold increased risk of failing treatment at multivariate analysis compared to patients without tumour (OR 8.49; 95\%CI: 3.90-18.49; $P<0.001$ ). Interestingly, none of the wellknown factors correlated with a lower SVR, and not even inadequate treatment regimens could explain the difference between the two groups. A possible explanation could be that HCC may serve as a sanctuary for $\mathrm{HCV}$, where virus particles can evade DAAs, as already known for HBV cccDNA; it is also possible that DAAs may be unequally distributed within fibrotic areas, generated for instance after some loco-regional treatment, radioembolization above all, due to the decreased blood flow.

Very recently, a review by Konjeti and John ${ }^{[46]}$ on DAAs and HCC presence/occurrence suggested deferring IFN-free therapy until complete radiological response to HCC curative treatment. Therefore HCV eradication with DAAs is still recommended in patients with history of treated HCC, until proven otherwise by future studies.

Similar data (and similar explanations) to Prenner et al ${ }^{[45]}$ study was obtained through the analysis of a large cohort of HCC identified by Beste et al ${ }^{[47]}$ in the national Veterans Affairs health care system. This study also suggested that a greater likelihood of SVR after DAA treatment was reached in patients with HCC history undergoing LT. This evidence is not fully explained by clinical reasons.

What is the most effective timing to offer HCV treatment in patients listed for LT, whether it is better to do so before or after LT, still remain open questions. Finally, another matter has been investigated: does SVR really matter in in the progression of liver disease? Nahon et al. ${ }^{[48]}$, in a multi-centre French cohort of 1323 Child A patients, mostly treated with IFN-based therapy, reported that viral eradication and achievement of SVR was associated with a significant reduction of HCC incidence (HR: 0.29; 95\%CI: 0.19-0.43; $P<0.001$ ). They also noticed that SVR was associated with a reduction in both liver- and non-liver-related mortality (HR: 0.27; 95\%CI: 0.18-0.42; $P<0.001)$. Petta et al. ${ }^{[49]}$ seem to have come to the same conclusions: in an Italian study of $535 \mathrm{HCV}$ cirrhotic patients, there was a reduction in disease progression and liver related mortality with the achievement of SVR. More specifically, the data of this report demonstrated a reduced incidence of 
hepatic decompensation and HCC development, with a lower likelihood of liver related death at 10 years, in association with achievement of $\mathrm{SVR}^{[49]}$. Similar findings were reported in the Hepatitis Testers cohort from North America ${ }^{[50]}$. In the multivariable model, SVR was associated with reduced liver cancer risk (HR: 0.20; 95\%CI: 0.13-0.30) in a median follow-up of 5.6 years.

\section{DISCUSSION}

The main points of strength of the previously mentioned studies are their prospective design and the large number of patients enrolled and the long follow-up. The largest studies included patients treated with IFNbased regimes and therefore a confirmation with DAA-based treatment only is needed.

Camma et al. ${ }^{[51]}$ considered Reig's observations as premature, affirmed that a comparison with untreated controls is mandatory to solve the issue without generating excessive alarm on DAAs; Nault and Colombo ${ }^{[16]}$, at the same time, did not consider the data published solid enough to confirm the increased risk in treated patients, even though they could recommend HCC surveillance after viral eradication; Alberti and Piovesan ${ }^{[52]}$ underlined the great variability in occurrence and in recurrence rates, reflecting the extreme heterogeneity of the different clinical settings and patient cohorts on which studies were based; finally, Blanco and Rivero-Juarez ${ }^{[53]}$ specified that prospective studies targeted on this problem are necessary before even considering a different therapeutic approach to patients with HCV-related liver disease.

Furthermore, the development of an aggressive tumor has been reported in some of patients ${ }^{[42]}$, although the authors cannot exclude that what they observed in these patients merely reflects the natural history of their liver disease. It is important to point out that the current clinical practice does not include IFNbased treatment any more, due to the important improvement in HCV-treatment made by DAAs. As a consequence, to compare DAA treatments with pre-DAA treatments or no treatment is meaningless. Nevertheless, the lack of randomized control trials is an important clinical and methodological issue. In conclusion, the risk reduction in hepatic decompensation as well as in HCC incidence in patients achieving SVR is the only proven evidence. The reports about the increased risk of HCC occurrence/recurrence in DAA treated patients are afflicted by selection and methodologic biases, that weaken the impact of these studies. We strongly believe that is mandatory to treat HCV-infected patients with DAAs but also to maintain an active surveillance for liver cancer as the guidelines suggest; the previously presented data must be considered with caution.

\section{DECLARATIONS}

\section{Authors' contributions}

Wroted the review and approved the final version: Russo FP, Tessari M, Imondi A

Edited the English: Lynch EN

Edited the manuscript and approved the final version: Farinati F

\section{Availability of data and materials}

Not applicable.

\section{Finacial support and sponsorship}

None.

\section{Conflicts of interest}

The authors declare no conflicts of interest in association with this study.

\section{Ethical approval and consent to participate}

Not applicable. 


\section{Consent for publication}

Not applicable.

\section{Copyright}

(c) The Author(s) 2018.

\section{REFERENCES}

1. Sangiovanni A, Del Ninno E, Fasani P, De Fazio C, Ronchi G, Romeo R, Morabito A, De Franchis R, Colombo M. Increased survival of cirrhotic patients with a hepatocellular carcinoma detected during surveillance. Gastroenterology 2004;126:1005-14.

2. Lok AS, Seeff LB, Morgan TR, di Bisceglie AM, Sterling RK, Curto TM, Everson GT, Lindsay KL, Lee WM, Bonkovsky HL, Dienstag JL, Ghany MG, Morishima C, Goodman ZD; HALT-C Trial Group. Incidence of hepatocellular carcinoma and associated risk factors in hepatitis C-related advanced liver disease. Gastroenterology 2009;136:138-48.

3. Tada T, Kumada T, Toyoda H, Kiriyama S, Tanikawa M, Hisanaga Y, Kanamori A, Kitabatake S, Yama T, Tanaka J. Viral eradication reduces all-cause mortality in patients with chronic hepatitis $\mathrm{C}$ virus infection: a propensity score analysis. Liver Int 2016;36:817-26.

4. Bruno S, Di Marco V, Iavarone M, Roffi L, Crosignani A, Calvaruso V, Aghemo A, Cabibbo G, Viganò M, Boccaccio V, Craxí A, Colombo M, Maisonneuve P. Survival of patients with HCV cirrhosis and sustained virologic response is similar to the general population. J Hepatol 2016;64:1217-23.

5. Di Marco V, Calvaruso V, Ferraro D, Bavetta MG, Cabibbo G, Conte E, Cammà C, Grimaudo S, Pipitone RM, Simone F, Peralta S, Arini A, Craxì A. Effects of eradicating hepatitis $\mathrm{C}$ virus infection in patients with cirrhosis differ with stage of portal hypertension. Gastroenterology 2016;151:130-9.e2.

6. Morgan RL, Baack B, Smith BD, Yartel A, Pitasi M, Falck-Ytter Y. Eradication of hepatitis C virus infection and the development of hepatocellular carcinoma: a meta-analysis of observational studies. Ann Intern Med 2013;158:329-37.

7. El-Serag HB, Kanwal F, Richardson P, Kramer J. Risk of hepatocellular carcinoma after sustained virological response in Veterans with hepatitis C virus infection. Hepatology 2016;64:130-7.

8. Cabibbo G, Petta S, Barbara M, Missale G, Virdone R, Caturelli E, Piscaglia F, Morisco F, Colecchia A, Farinati F, Giannini E, Trevisani F, Craxì A, Colombo M, Cammà C; ITA.LI.CA study group. A meta-analysis of single HCV-untreated arm of studies evaluating outcomes after curative treatments of HCV-related hepatocellular carcinoma. Liver Int 2017;37:1157-66.

9. Falade-Nwulia O, Suarez-Cuervo C, Nelson DR, Fried MW, Segal JB, Sulkowski MS. Oral direct-acting agent therapy for hepatitis C virus Infection: a systematic review. Ann Intern Med 2017;166:637-48.

10. Reig M, Marino Z, Perello C, Inarrairaegui M, Ribeiro A, Lens S, Díaz A, Vilana R, Darnell A, Varela M, Sangro B, Calleja JL, Forns X, Bruix J. Unexpected high rate of early tumor recurrence in patients with HCV-related HCC undergoing interferon-free therapy. J Hepato 2016;65:719-26.

11. Conti F, Buonfiglioli F, Scuteri A, Crespi C, Bolondi L, Caraceni P, Foschi FG, Lenzi M, Mazzella G, Verucchi G, Andreone P, Brillanti S. Early occurrence and recurrence of hepatocellular carcinoma in HCV-related cirrhosis treated with direct-acting antivirals. J Hepato 2016;65:727-33.

12. Kozbial K, Moser S, Schwarzer R, Laferl H, Al-Zoairy R, Stauber R, Stättermayer AF, Beinhardt S, Graziadei I, Freissmuth C, Maieron A, Gschwantler M, Strasser M, Peck-Radosalvjevic M, Trauner M, Hofer H, Ferenci P. Unexpected high incidence of hepatocellular carcinoma in cirrhotic patients with sustained virologic response following interferon-free direct-acting antiviral treatment. J Hepatol 2016;65:856-8.

13. Bruix J, Gores GJ, Mazzaferro V. Hepatocellular carcinoma: clinical frontiers and perspectives. Gut 2014;63:844-55.

14. Harouaka D, Engle RE, Wollenberg K, Diaz G, Tice AB, Zamboni F, Govindarajan S, Alter H, Kleiner DE, Farci P. Diminished viral replication and compartmentalization of hepatitis C virus in hepatocellular carcinoma tissue. Proc Natl Acad Sci U S A 2016;113:1375-80.

15. Reig M, Boix L, Marino Z, Torres F, Forns X, Bruix J. Liver cancer emergence associated with antiviral treatment: an immune surveillance failure? Semin Liver Dis 2017;37:109-18.

16. Nault JC, Colombo M. Hepatocellular carcinoma and direct acting antiviral treatments: controversy after the revolution. J Hepatol 2016;65:663-5

17. Llovet JM, Villanueva A. Liver cancer: Effect of HCV clearance with direct-acting antiviral agents on HCC. Nat Rev Gastroenterol Hepato 2016;13:561-2.

18. Serti E, Chepa-Lotrea X, Kim YJ, Keane M, Fryzek N, Liang TJ, Ghany M, Rehermann B. Successful interferon-free therapy of chronic hepatitis C virus infection normalizes natural killer cell function. Gastroenterology 2015;149:190-200.e2.

19. Cardoso H, Vale AM, Rodrigues S, Goncalves R, Albuquerque A, Pereira P, Lopes S, Silva M, Andrade P, Morais R, Coelho R, Macedo $\mathrm{G}$. High incidence of hepatocellular carcinoma following successful interferon-free antiviral therapy for hepatitis $\mathrm{C}$ associated cirrhosis. $\mathrm{J}$ Hepatol 2016;65:1070-1.

20. Abdelaziz AO, Nabil MM, Abdelmaksoud AH, Shousha HI, Cordie AA, Hassan EM, Omran DA, Leithy R, Elbaz TM. De-novo versus recurrent hepatocellular carcinoma following direct-acting antiviral therapy for hepatitis C virus. Eur J Gastroenterol Hepatol 2018;30:3943.

21. ANRS collaborative study group on hepatocellular carcinoma (ANRS CO22 HEPATHER, CO12 CirVir and CO23 CUPILT cohorts). Lack of evidence of an effect of direct-acting antivirals on the recurrence of hepatocellular carcinoma: data from three ANRS cohorts. J Hepatol 2016;65:734-40.

22. Kolly P, Dufour JF. A strong message is needed to address the issue of HCC recurrence after DAA therapy. J Hepatol 2016;65:1268-9.

23. Carrat F, Nahon P, Duclos-Vallee JC, Pageaux GP, Fontaine H, Pol S; ANRS collaborative study group on hepatocellular carcinoma (ANRS CO22 HEPATHER, CO12 CirVir and CO23 CUPILT cohorts). Reply to "A strong message is needed to address the issue of HCC 
recurrence after DAA therapy". J Hepatol 2016;65:1269-70.

24. Cheung MCM, Walker AJ, Hudson BE, Verma S, McLauchlan J, Mutimer DJ, Brown A, Gelson WTH, MacDonald DC, Agarwal K, Foster GR, Irving WL; HCV Research UK. Outcomes after successful direct-acting antiviral therapy for patients with chronic hepatitis $\mathrm{C}$ and decompensated cirrhosis. J Hepatol 2016;65:741-7.

25. Torres HA, Vauthey JN, Economides MP, Mahale P, Kaseb A. Hepatocellular carcinoma recurrence after treatment with direct-acting antivirals: first, do no harm by withdrawing treatment. J Hepatol 2016;65:862-4.

26. Zavaglia C, Okolicsanyi S, Cesarini L, Mazzarelli C, Pontecorvi V, Ciaccio A, Strazzabosco M, Belli LS. Is the risk of neoplastic recurrence increased after prescribing direct-acting antivirals for HCV patients whose HCC was previously cured? J Hepatol 2017;66:236-7.

27. Cabibbo G, Petta S, Calvaruso V, Cacciola I, Cannavo MR, Madonia S, Distefano M, Larocca L, Prestileo T, Tinè F, Bertino G, Giannitrapani L, Benanti F, Licata A, Scalisi I, Mazzola G, Cartabellotta F, Alessi N, Barbàra M, Russello M, Scifo G, Squadrito G, Raimondo G, Craxì A, Di Marco V, Cammà C; Rete Sicilia Selezione Terapia - HCV (RESIST-HCV). Is early recurrence of hepatocellular carcinoma in HCV cirrhotic patients affected by treatment with direct-acting antivirals? A prospective multicentre study. Aliment Pharmacol Ther 2017;46:688-95.

28. Waziry R, Hajarizadeh B, Grebely J, Amin J, Law M, Danta M, George J, Dore GJ. Hepatocellular carcinoma risk following direct-acting antiviral HCV therapy: a systematic review, meta-analyses, and meta-regression. J Hepatol 2017;67:1204-12.

29. Ioannou GN, Green PK, Berry K. HCV eradication induced by direct-acting antiviral agents reduces the risk of hepatocellular carcinoma. J Hepatol 2017; doi: 10.1016/j.jhep.2017.08.030.

30. Maan R, Feld JJ. Risk for hepatocellular carcinoma after hepatitis C virus antiviral therapy with direct-acting antivirals: case closed? Gastroenterology 2017;153:890-2.

31. Kobayashi M, Suzuki F, Fujiyama S, Kawamura Y, Sezaki H, Hosaka T, Akuta N, Suzuki Y, Saitoh S, Arase Y, Ikeda K, Kumada H. Sustained virologic response by direct antiviral agents reduces the incidence of hepatocellular carcinoma in patients with HCV infection. J Med Virol 2017;89:476-83.

32. Kolly P, Waidmann O, Vermehren J, Moreno C, Vogeli I, Berg T, Semela D, Zeuzem S, Dufour JF. Hepatocellular carcinoma recurrence after direct antiviral agent treatment: a European multicentre study. J Hepatol 2017;67:876-8.

33. Petta S, Cabibbo G, Barbara M, Attardo S, Bucci L, Farinati F, Giannini EG, Tovoli F, Ciccarese F, Rapaccini GL, Di Marco M, Caturelli E, Zoli M, Borzio F, Sacco R, Virdone R, Marra F, Felder M, Morisco F, Benvegnù L, Gasbarrini A, Svegliati-Baroni G, Foschi FG, Olivani A, Masotto A, Nardone G, Colecchia A, Persico M, Boccaccio V, Craxì A, Bruno S, Trevisani F, Cammà C; Italian Liver Cancer (ITA.LI.CA) Group. Hepatocellular carcinoma recurrence in patients with curative resection or ablation: impact of HCV eradication does not depend on the use of interferon. Aliment Pharmacol Ther 2017;45:160-8.

34. Kanwal F, Kramer J, Asch SM, Chayanupatkul M, Cao Y, El-Serag HB. Risk of hepatocellular cancer in HCV patients treated with directacting antiviral agents. Gastroenterology 2017;153:996-1005.e1.

35. Li DK, Ren Y, Fierer DS, Rutledge S, Shaikh OS, Lo Re V 3rd, Simon T, Abou-Samra AB, Chung RT, Butt AA. The short-term incidence of hepatocellular carcinoma is not increased after hepatitis $\mathrm{C}$ treatment with direct-acting antivirals: an ERCHIVES study. Hepatology 2018;67:2244-53.

36. Singer AW, Reddy KR, Telep LE, Osinusi AO, Brainard DM, Buti M, Chokkalingam AP. Direct-acting antiviral treatment for hepatitis C virus infection and risk of incident liver cancer: a retrospective cohort study. Aliment Pharmacol Ther 2018;47:1278-87.

37. Li DK, Chung RT. Impact of hepatitis C virus eradication on hepatocellular carcinogenesis. Cancer 2015;121:2874-82.

38. Yang JD, Aqel BA, Pungpapong S, Gores GJ, Roberts LR, Leise MD. Direct acting antiviral therapy and tumor recurrence after liver transplantation for hepatitis C-associated hepatocellular carcinoma. J Hepatol 2016;65:859-60.

39. Belli LS, Berenguer M, Cortesi PA, Strazzabosco M, Rockenschaub SR, Martini S, Morelli C, Donato F, Volpes R, Pageaux GP, Coilly A, Fagiuoli S, Amaddeo G, Perricone G, Vinaixa C, Berlakovich G, Facchetti R, Polak W, Muiesan P, Duvoux C; European Liver and Intestine Association (ELITA). Delisting of liver transplant candidates with chronic hepatitis C after viral eradication: a European study. J Hepatol 2016;65:524-31.

40. Pascasio JM, Vinaixa C, Ferrer MT, Colmenero J, Rubin A, Castells L, Manzano ML, Lorente S, Testillano M, Xiol X, Molina E, GonzálezDiéguez L, Otón E, Pascual S, Santos B, Herrero JI, Salcedo M, Montero JL, Sánchez-Antolín G, Narváez I, Nogueras F, Giráldez Á, Prieto M, Forns X, Londoño MC. Clinical outcomes of patients undergoing antiviral therapy while awaiting liver transplantation. J Hepatol 2017:67:1168-76.

41. Zanetto A, Shalaby S, Vitale A, Mescoli C, Ferrarese A, Gambato M, Franceschet E, Germani G, Senzolo M, Romano A, Angeli P, Rugge M, Farinati F, Forton DM, Cillo U, Burra P, Russo FP. Dropout rate from the liver transplant waiting list because of hepatocellular carcinoma progression in hepatitis C virus-infected patients treated with direct-acting antivirals. Liver Transpl 2017;23:1103-12.

42. Romano A, Piovesan S, Anastassopoulos G, Chemello L, Cavalletto L, Russo FP, Gambato M, Vincenzi V, Scotton P, Panese S, Tempesta D, Bertin T, Carrara M, Carlotto A, Capra F, Carolo G, Scroccaro G, Alberti A, Navigatore Study Group. Incidence and pattern of "de novo" hepatocellular carcinoma in HCV patients treated with oral DAAs. Hepatology 2016;64:10A.

43. Nakao Y, Hashimoto S, Abiru S, Komori A, Yamasaki K, Nagaoka S, Saeki A, Bekki S, Kugiyama Y, Kuroki T, Ito M, Nakao K, Yatsuhashi H. Rapidly growing, moderately differentiated HCC: a clinicopathological characteristic of HCC occurrence after IFN-free DAA therapy? J Hepatol 2017; doi: 10.1016/j.jhep.2017.11.011.

44. Debes JD, van Tilborg M, Groothuismink ZMA, Hansen BE, Schulze Zur Wiesch J, von Felden J, de Knegt RJ, Boonstra A. Levels of cytokines in serum associate with development of hepatocellular carcinoma in patients with HCV infection treated with direct-acting antivirals. Gastroenterology 2018;154:515-7.e3.

45. Prenner SB, VanWagner LB, Flamm SL, Salem R, Lewandowski RJ, Kulik L. Hepatocellular carcinoma decreases the chance of successful hepatitis C virus therapy with direct-acting antivirals. J Hepatol 2017;66:1173-81.

46. Konjeti VR, John BV. Interaction between hepatocellular carcinoma and hepatitis C eradication with direct-acting antiviral therapy. Curr Treat Options Gastroenterol 2018;16:203-14.

47. Beste LA, Green PK, Berry K, Kogut MJ, Allison SK, Ioannou GN. Effectiveness of hepatitis C antiviral treatment in a USA cohort of 
veteran patients with hepatocellular carcinoma. J Hepatol 2017;67:32-9.

48. Nahon P, Bourcier V, Layese R, Audureau E, Cagnot C, Marcellin P, Guyader D, Fontaine H, Larrey D, De Lédinghen V, Ouzan D, Zoulim F, Roulot D, Tran A, Bronowicki JP, Zarski JP, Leroy V, Riachi G, Calès P, Péron JM, Alric L, Bourlière M, Mathurin P, Dharancy S, Blanc JF, Abergel A, Serfaty L, Mallat A, Grangé JD, Attali P, Bacq Y, Wartelle C, Dao T, Benhamou Y, Pilette C, Silvain C, Christidis C, Capron D, Bernard-Chabert B, Zucman D, Di Martino V, Thibaut V, Salmon D, Ziol M, Sutton A, Pol S, Roudot-Thoraval F; ANRS CO12 CirVir Group. Eradication of hepatitis C virus infection in patients with cirrhosis reduces risk of liver and non-liver complications. Gastroenterology 2017;152:142-56.e2.

49. Petta S, Di Marco V, Bruno S, Enea M, Calvaruso V, Boccaccio V, Rossi S, Craxì A, Cammà C. Impact of virus eradication in patients with compensated hepatitis C virus-related cirrhosis: competing risks and multistate model. Liver Int 2016;36:1765-73.

50. Islam N, Krajden M, Shoveller J, Gustafson P, Gilbert M, Buxton J, Wong J, Tyndall T, Janjua NZ, BC-HTC Team. Impact of drug use and opioid substitution therapy on hepatitis C reinfection: The BC Hepatitis Testers Cohort. Hepatology 2016;64:31 A.

51. Camma C, Cabibbo G, Craxi A. Direct antiviral agents and risk for HCC early recurrence: much ado about nothing. J Hepatol 2016;65:8612 .

52. Alberti A, Piovesan S. Increased incidence of liver cancer after successful DAA treatment of chronic hepatitis C: fact or fiction? Liver Int 2017;37:802-8.

53. Blanco JR, Rivero-Juarez A. The risk of hepatocellular carcinoma after sustained virological response in patients treated with the new directacting antiviral drugs: should we be worry about it? Expert Rev Anti Infect Ther 2016;14:993-6. 